\title{
Shaping Consciousness in Kindergarten. Conformity to School Norms through the Formation of a Child's Story
}

\author{
Maria Poimenidou ${ }^{1} \&$ Maria Papadopoulou ${ }^{1}$ \\ ${ }^{1}$ School of Humanities, Department of Early Childhood Education, University of Thessaly, Greece \\ Correspondence: Maria Poimenidou, School of Humanities, Department of Early Childhood Education, \\ Argonafton \& Philellinon, 38221, Volos, Greece. Tel: 30-242-107-4750. E-mail: mpoimenidou@uth.gr
}

Received: October 20, 2012 Accepted: November 19, 2012 Online Published: December 11, 2012

doi:10.5539/ies.v6n1p166

URL: http://dx.doi.org/10.5539/ies.v6n1p166

\begin{abstract}
Communication is a multidimensional process. No matter what the field of the interaction is, there is always a crucial point in terms of the negotiation of social roles. This becomes more apparent in the field of education where institutional norms influence not only the children's behaviour, but at the same time the shaping of their consciousness. In this paper, we analyse the interaction between a pupil and his teacher. The field of the activity is a recount of a pupil's weekend. The aim of this study was to analyze the implicit negotiation of the appropriate behaviour and the socialization according to the school norms. The process of socialization, as it is presented in social psychology, is analysed through the selective use of Systemic Functional Grammar. This methodological combination revealed the way linguistic choices and the construction of the story reflected the formation of the child's social identity.
\end{abstract}

Keywords: social roles, linguistic practices, conformity, shaping of consciousness, kindergartens

\section{Introduction}

\subsection{Communication and Meaning Negotiation}

Linguistic practices of every contemporary society are formulated by societies' communicative needs (Swales, 1990). Bakthin (2003) attributed the term 'genre' to those linguistic practices which develop in stable structures of a society. The stability of their structure makes genres predictable and, at the same time, facilitates communication in terms of discourse comprehension and production (Macken - Horarick, 1998; Freedman \& Medway, 1994). Genre, as it has been analyzed by J. Martin (1984) and his colleagues illustrated the way social purposes are embedded in language. Different human activities, social environments and ways to communicate are reflected in the multiple ways of using language and affect the structure of genres. Following Halliday's (1994) Systemic Functional Theory (SFL), the analysis of genres and its linguistic recourses provides the opportunity to connect language, culture and ideology (Martin \& Rose, 2007).

Nevertheless, discourse production constitutes a dynamic process, allowing the expression of social stances which are in a constant change, shaping new ways of viewing and perceiving the world. Bakthin, (2003) identified the phenomenon of heteroglossia in the communication process, where on the one hand centripetal forces, located in the same language, attempt to maintain dominant discourses and, on the other hand, centrifugal forces express new social tendencies. According to Bakthin (2003), this is a process that, in its diachronic aspect, reveals the connection of language, ideology and personal point of view for the world. The recognition of the dominance of linguistic practices in societies gave rise to new orientations in contemporary linguistic approaches concerning the study of genres. In this context, genres are not regarded as taxonomies, isolated and distinguished types, but as cartography of social, linguistic practices used for the achievement of various goals. Therefore, the study of genres is presented through the topological approach, according to which both similarities and differences among genres are identified. In fact, contiguities are the key to comprehending the osmosis in text structure and lexicogrammar. Although genres function as models for language production, they also constitute a tool, which can be differentiated according to the communicative needs of the language users. An illustrative example is how you can perceive storytelling. Storytelling is a very common element in every culture; however, the message of every story focuses on a particular point of view. Plum's work indicated four genres that contributed to achieving the social function of storytelling: Narrative, Anecdote, Exemplum and Recount (Plum, 1988; Eggins and Slade, 1997). All four genres are based on narration in a temporal order but they have different 
structures and lexico-grammatical features. Their differences arise from their communicative goal, the main motive of the speaker. For example, a Recount consists of a retelling of an event while an Exemplum declares a point of view indicating what is right or wrong. Their differences become apparent in their generic structure. While the middle stages of the Recount are the Record of Events and the Reorientation, in Exemplum we have the Incident -a stage similar to the Record of Events- which is followed by an Interpretation -a distinctive stage that is oriented to an ethic perception of the world. An exhaustive research on different cultures can reveal more genres, for example, fables and parables (Martin \& Rose, 2007).

Every day communication, except for the events with a clear pragmatic orientation, contributes to value and knowledge proliferation (Halliday, 1978) and the formation of a common view of the world (Eggins \& Slade, 1997). The main practice in a casual conversation is storytelling (Bernstein, 1990; Bruner, 1986; Eggins \& Slade, 1997), which takes the form of a monologue or a dialogue known as 'conversational narratives' (Ochs, 1997). It is a common belief that the audience plays an important role in the narration shaping, as it is mainly about a collection process rather than a depiction of events. In fact, the possible disparities that arise depending on the communicative event contribute to meaning negotiation in social context.

\subsection{Communication and Identity Shaping}

Success in communication is contingent on participants' ability to take into consideration other peoples' view. This is an interactional process, which downplays egocentrism, as it was introduced by Piaget, and shapes both the communication and the participants. According to social psychology, the lifelong social interaction constitutes human identities (Hewitt, 2007). Both the status of the participants in the communication process and the context in which the communication takes place are crucial factors for interaction (Fairclough, 1995). However, only in the case of equality the participants have the same rights and obligations in the communicative event. Research (Taylor, 1995; Ochs \& Taylor, 1992) indicated that the social context determines the role and the participation of the interlocutors in story construction not only in public but also in private life. Namely, the construction of oral texts constitutes a process of negotiating personal relations. The enactment of interpersonal meaning can be traced in interaction and, at the same time, it reveals the coexistence of communicative goals. For instance, regarding narrations addressed to children, their primary aim is to help children comprehend "what is expected, normal and appropriate». In addition, research (Scheibe, 1995) demonstrated that the element of adventure characterizes male narrations in the west, a feature that is inextricably linked with the need for masculinity promotion. Thus, narrations and, at the same time, the image of self are constructed through this process. That comes because individuals develop the notion of self by coming to view themselves as they are seen by others.

\subsection{Interactions in the Field of Education}

Education plays an important role in the formation of social identity but at the same time it triggers inequality among members of a society. A powerful resistance to this inequality constitutes the critical pedagogy (Freire, Giroux), which reveals the role of dominance in the acceptance and perpetuation of the prevalent ideology. According to Bernstein (1996), the way in which ideology exerts influence on education needs to be explored, in order to reveal the ways the transmission of ideology is implemented in education. Linguistic practices that impose dominance have been investigated in the field of SFL research (Lemke, 1985; Martin \& Rose, 2007) aiming at boosting citizens' role in society. This prospect is intertwined with the concept that political change draws on individuals that can have a leading role and develops into a context of dialogism (Martin \& Rose, 2007). This pedagogy augments the repertoire of learners, a competence that provides the means for ontogenesis.

Socialization is based on the acceptance of rules and is directly observable by a change in learners' behavior (Abrahamson, 1966). Nonetheless, that external conformity leads to internal conformity. This process can be perceived as an internalization of social order and the creation of habitus (Bourdieu, 1990). That means that perception and behavior are guided by the acceptance of the official perspective. Traditionally in education, pedagogic practice establishes the asymmetry of social roles through hierarchical rules in either explicit or implicit social relation (Bernstein, 2003). The most crucial step for pupils is to accept the dominance of the teacher as the transmitter of knowledge. Preschool education, in particular, constitutes an institutional frame with special features allowing for the open curriculum and children-initiated activities. In any case, the kindergarten teacher holds a prominent position in the pedagogical process, as his/her supportive role is the key to learners' development, while his/her regulative discourse contributes to the child's socialization and its integration in the group. In this context, Christie (2002) acknowledged the dominant function of pedagogical discourse in kindergarten in terms of 'consciousness formation'. 
The kindergarten curriculum consists of two frames; the first refers to optional activities chosen by children, while the second includes pre-planned educational activities. Every frame poses different prerequisites for the children's participation, and is assessed by different criteria too. Nonetheless, it is not certain whether children of pre-school age are aware of the limits and the functions of both frames. A typical example is the 'play', whose use and functions are not easily perceived by children of low socio-economical status in both frames of the curriculum (Cooper \& Dunne, 2000). Another activity that falls between these two frames is the "sharing time". "Sharing time" draws on the children spontaneous participation and their willingness to share narrations that refer to important events concerning their classmates. The aim of the activity is to facilitate children's interaction and consolidate their relationships and team spirit. In fact, it is an activity, which empowers every child's role in the communication process with peers and, simultaneously, contributes to the development of the child's linguistic repertory (Christie, 2002). However, research has indicated that it is an activity which is assessed by teachers either directly or indirectly. That is because teachers' regulative discourse dominates informal just as formal activities.

\subsection{Hypotheses of the Research}

Educational context exerts pressure on students to adopt its norms and this pressure is hidden in discourse structures (van Dijk, 2008). The dynamic evolution of the dialogue we analyze and the situational context constitute a pathway to the interpretation of the stance of the participants. The present study focuses on student's discourse and the deviation from the expected generic structure. It is a critical approach to classroom discourse that pursues to grasp the ongoing evaluation that designates the structure of the activity.

The research questions are:

In what way are the teacher's comments incorporated into the student's narration?

What attitudes and behaviors can be traced in the modification of the student's discourse?

\section{Method}

\subsection{Research Setting}

The study concentrated on an episode occurred during an informal activity in a kindergarten. The group consisted of sixteen (16) pupils aged 5 to 6.2 years old. The kindergarten was in a village near a small town, in a rural area. The teacher was experienced, with a sincere concern for her pupils. The researcher held the role of a non interfering observer.

The "Sharing time" was a common activity for the class and was taking place every Monday morning. In the same class we recorded 'sharing time' activities 3 times from February to May 2005. Usually, the activity was not raising the children's interest and their verbal participation was limited to few sentences. The sample confirms that it is an area that a teacher cannot manage easily. Children's spontaneous stories provoked embarrassment to the teacher who unsuccessfully insisted on expanding the field of the stories.

The narration we focused on is part of an activity where the participation was based on each child's decision. Each child took the step and presented a story of the weekend. Although it is referred to as a monologic activity, the teacher often interfered in this class. She attempted to help the children complete their narration. Alexis, the narrator of the story analyzed, was the last but one pupil that participated in the activity and seemed competent to do so.

\subsection{The Framework of Data Analysis}

Ethnographic research and discourse analysis have shown that learning contexts are immanently hybrid (Gutierrez, Baquedano - Lopez and Tejeda, 1999). The hybridism derives from the existence of different 'voices' in the classroom (Bakthin, 2003; Bernstein, 1990).

The present research drawing on earlier work on the deviation of genres in educational activities (Papadopoulou \& Poimenidou, 2008), aimed to explore how the pedagogic discourse, especially the regulative discourse, contributed to the reproduction of social norms. The text analyzed here was a narration of a preschooler during the 'sharing time' activity. It is a case study that deals with the consequences of the teacher's comments on the linguistic instantiation of the pupil's narrative. The analysis occurred in two axes: a) the role of the teacher's interventions in the construction of the story $b$ ) their role in the socialization regarding school norms.

We elaborated on the first axis through the selective use of Systemic Functional Grammar and Genre Theory. We focused on the structure of the text, its stages and lexicogrammar choices. This process gave us the opportunity to capture, through language's metafunction, the instances of dialogic exchanges that created deviation from the presentation of child's experiences. In our analysis, we followed Plum's research on 
narratives (1988). His categories can illustrate the different structures and functions of storytelling and have been adopted previously for the analysis of children stories (Martin and Rothery, 1986; Christie, 2002).

The second axis distinguished the two frames, or two 'voices', in the same context: the institutional, which was represented by the teacher, and the personal that was represented by the peer group. We used the tripartite scheme of socialization continuum (Abrahamson, 1966) to study the attitudes throughout the communication event and finally the stance of the narrator. As it is illustrated in Figure 1, socialization is a process that begins within a context that emits required behavior. The next stage, conformity, is the attitude that provides the modification of the norms, while institutionalization refers to the adoption of the norms.

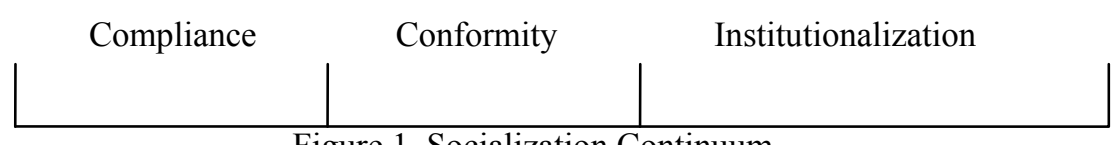

Figure 1. Socialization Continuum

The combination of the axes of meaning and attitude in every episode of the communication presents the deviation from personal voice and the hybridization of the story.

\section{Results}

\subsection{The Construction of the Story}

The narration presented below began at the moment the teacher nominated the speaker and the group waited to hear the news. Alexis was the last but one pupil who had been waiting for his turn for almost half an hour.

1. T- Alexis, now you tell us how you spent your time.

2. A- I went down and I went to...

3. T- Where did you go?

4. A- I changed my clothes and I went... (he stops and looks down thinking)

5. T - Stand up. Stand up. Here, so that we can hear you. We can't hear you.

Alexis began his narration but it seemed he wasn't ready enough. The teacher, activated by the child's silence, posed the first question. Although Alexis continued the story, soon he stopped again. The next notion of the teacher suggested that Alexis should try to be audible. This notion is very common in this kind of activity and facilitates pupils' concentration on the activity (Christie, 2002):

\section{Stand up. Stand up. Here, so that we can hear you. We can't hear you.}

The teacher demanded a certain attitude from the pupil. The demand was not reflected only on the meaning of the teacher's comments. It also affected the structure of her statement that consisted of four short clauses while the first two of them were elliptical. This structure boosted the speech function. The imperative form of the two clauses confirmed the dominant role of the teacher. While she was talking about the physical position of Alexis, what really worried her were the pauses in the activity. The regulation of time was very important for the audience. The set of the pace can be connected with the rhythm of the comments.

As Alexis started his story, he had already picked an episode to present to his classmates. The pace was rather slow so we can suppose that he needed time to organize his story. In the beginning, he didn't present the time that the episode took place, because it was defined by his teacher. He didn't present the place either. This was because evidence of his story revealed that it occurred at his house. The information of the place has so far been hidden in the notion: I changed my clothes. It is obvious for a child that an act like that can take place only at home.

6. A- And all this stuff my father had, I took them and the jackhammer and I went back there and I dug.

Alexis presented a remarkable episode in the Abstract. A jackhammer is a tool that is kept away from children and at the same time it is the tool that makes Alexis a man. The field of the narration was not the expected. The deviation from of the norms of children's activities made the teacher interrupt the narration.

7. T- With the jackhammer? Isn't it that dangerous?

8. A- But I was holding it right.

9. T- The jackhammer? 
10. A- Yes.

11. T- That big one? Wasn't it heavy?

12. A- It wasn't big. It was small.

13. T- And you take such tools?

14. A- Yes.

15. T- Those are dangerous.

16. P- I don't touch them. I just watch my dad.

The teacher interfered in Alexis' narration. She posed a series of questions, many of which required confirmation: With the jackhammer? (etc). Other questions demanded the expression of an opinion through the insertion of a descriptive adjective epithet (Attribute): Isn't it that dangerous? That big one? Wasn't it heavy? The questions that the teacher posed were of great significance for the regulation of pupils' behavior. Within the pragmatic orientation of the questions we can capture the negotiation of values and stances. This dimension revealed the real function of the questions in the construction of the interpersonal meaning. The asymmetry of the interpersonal roles gave her the right to doubt on the evidence of Alexis story.

Alexis expressed his own opinion: It wasn't big. It was small. Through this statement he negotiated a quality. The enactment of the Appreciation was used for the amplification of his argumentation. In order to present a convincing story, he focused on the size. This option was based on the correspondence with his own size.

The teacher insisted on doubting the option of Alexis and after some questions she came back with a declarative statement: Those are dangerous. This move was indicative of the authoritarian teacher's role as the expert of the class. The voice of the teacher was amplified by another pupil's intervention that assured her comments. In this controversial moment of the dialogue, Alexis chose two modes to support his story. A rhetoric and a thematic one.

17. A- Can I tell you what my father told me to do with the jackhammer? (Addressing to his teacher) This jackhammer is small. He told me to punch all the sides with the jackhammer and then put some screws.

He addressed a rhetoric question to his teacher. In this way, he invoked his role as a narrator in order to mitigate his teacher's interference. At the same time, he altered the intransitive process of his story to transitive. Alexis was not the only Actor of the story. He introduced his father and he assured his teacher that he acted under his father's supervision. These two options gave him the opportunity to continue his story, extending his role as a capable person.

18. T- Your father told you that? Then, what else did you do?

19. A- And after that, my father told me to bring him the lockl, the clock so that he can put it.

20. T- Clock. Did you put the clock?

21. A- To put the clock out there.

22. T- What is this clock? The one we can see the time on?

23. A - Not that one. The other one we put outside. It's big.

24. T- A big clock. Right? And what does this clock do?

25. A- And then I screwed it with the screws and then we put the radiator that I was bringing from the things my dad told me and...

26. T- So you helped your dad.

27. A- Yes. Though some of them were dangerous, I fixed them. I was bringing them to my dad and I didn't fix them.

28. T- You gave them to your dad. You helped. You weren't touching them because they are dangerous.

The rhetoric capacity of Alexis and his father's hitch in the field of the story modified the role of the teacher. The teacher's constant questions contributed to the construction of the meaning. Alexis made a move in order to be in agreement with his teacher's remarks. Yes. Though some of them were dangerous, I fixed them. I was bringing them to my dad and I didn't fix them. He confirmed the role of the assistant that his teacher brought out. The teacher concluded repeating the setting. Finally, she ensured Alexis that she acknowledged the deviation from the story. I see. 
29. A- And another day, I had seen a small kid holding the big jackhammer and it fell on its legs and broke them.

Surprisingly, Alexis made another move which ensured another kind of deviation from (in) his story. He added another incident to his story. This stage posed his story to the genre of 'exemplum' and made the acceptance of his teacher's opinion explicit. The story ended with reconciliation.

30. T- You saw how dangerous that is, right?

31. A- But we have a fa- ours was a small one.

32. T- Oh! It was small like a fake one.

Teacher recognized Alexis' intention to accept the social norms and she helped him to complete the story. In the story analyzed we can indentify the stages:

Orientation ^ Record of Events ^ Interpretation ^ Coda

Two shifts made the story a hybrid genre. The first one was the fiction word that Alexis presented in the Orientation (jackhammer) and he continued to construct in the next stage. The next one was the reconciliation offered by Alexis in the Interpretation stage. Even though the teacher's interference modified the story, we can undoubtedly claim that the pupil's intension was to present a remarkable event and not to introduce an appropriate behavior.

\subsection{The Socialization According to School Norms}

Conversational exchanges shaped the story the way we indicated in the above analysis. We revealed the relocation of the story and the role of the teacher's comments in this route. In addition, we analyzed Alexis' stance and attitudes. We represented the different ways Alexis was situated in his class and finally we connected these positions to the Socialization Continuum.

The narrator (A) acted as a member of a peer group (P) and tried to highlight his masculinity through his strength in order to capture the admiration of the kindergartens (Figure 2). His teacher's insistence made him reconsider the different role of his audience. He felt the pressure of his teacher's guidance. He realized that the context was not only the peer group (Figure 3). His teacher ( $\mathrm{T}$ ) had her own role in the activity. As the pressure increased, Alexis came closer to his teacher's view. He reconsidered his own version of the story and adopted the recommendations made by his teacher. It was an internal process that transferred him beside his teacher (Figure 4). The stage of the Interpretation assured the change in Alexis' attitude (Figure 5).

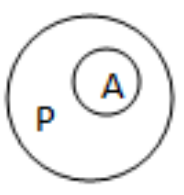

Figure 2.

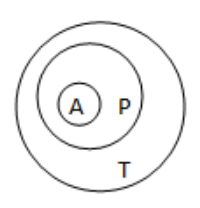

Figure 3.

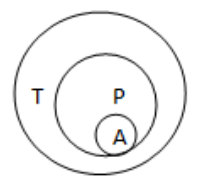

Figure 4.

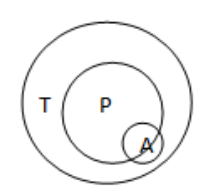

Figure 5.

The complication of the story was formed in consensus with the teacher's comments. But the most important function of the regulative discourse was the socialization of Alexis according to school norms. In Figure 6, we represent the process of socialization.

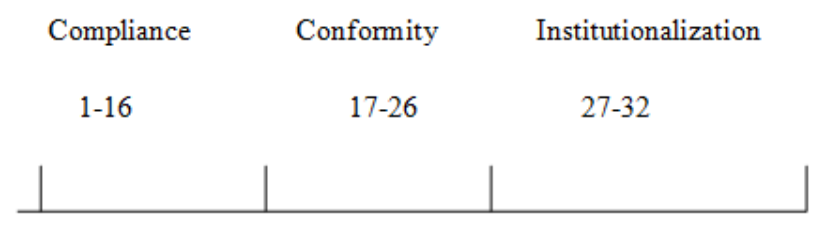

Figure 6.

We can visualize the schematic structure of the text according to the stance of the narrator. In Figure 7, we present the regulative discourse and the evolution of the story. 


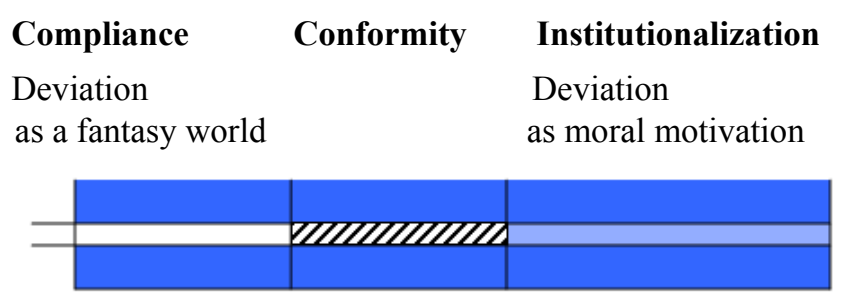

Figure 7.

\section{Discussion}

The above analysis illustrated the linguistic and social recourses which were activated during an informal educational activity. The first step of analysis focused on the role of the narrator in relation to the class contexts. At the beginning of the activity, the peer group, represented by the kindergartens, was the only context identified by the actor. This perception can be connected with the informal character of the activity. The addressee acknowledged the peer's group as the audience and consequently, in this stage, narration was based on children's imaginary world. This finding confirmed the children's exploration of social roles in order to pursue their own social identity (Lyle, 2002).

In addition, the interference of the teacher altered the monologic mode of the activity. In this way, it created another image of the classroom revealing the co - existing institutional context. This context was represented by the teacher's voice and it declared its norms through the regulation of the narration. This stage could be regarded as a conversational narration, although it was a different procedure from the one identified in casual conversation (Eggins \& Slade 1997). In the educational context, the domination of the teacher's voice was not a matter of negotiation (Christie, 2002). In contrast, a child must be ready to argue about the subject - matter of his story and even to reconsider it. The deviation from the generic structure of the story was based solely on the teacher's power. This stage was the crucial feature that confirmed the teacher's power and made the narration initially accepted and finally successful.

The other aspect established by the regulative discourse referred to the conventional roles. Students were constantly reminded that the teacher was the only authority of the class. The social asymmetry of the interpersonal roles, in other words the domination of teacher, was registered in the construction of the story. The teacher's regulative discourse posed the norms for the time management and the exclusion of the unrealistic properties.

However, the crucial matter that was under negotiation was the student's moral regulation and social location. This situational context demolished the boundaries of infancy and established a new social identity for the student. The context's pressure became an internal procedure that differentiated the patterns of acceptable behaviour and the view of the world. In the above analysis, the linguistic capacities of the child opened up the opportunity to negotiate and sustain the role of the narrator. At the same time, this negotiation was a procedure of cognition on what was properly expected by the child. The student's identity was constructed through the enactment of the conventional perception of the role. This route established the hierarchical rules which aimed at the acceptance of order, the adoption of certain manner and the shaping of character (Bernstein, 2003).

Two kinds of deviation were captured in the activity. The first one was a phenomenon which was based on early childhood as an unofficial discourse. In this context, meaning was not founded in the real world. The construction of the story was a process for exploring the world and the personal identity.

The second type was an act of correspondence with the educational context and its norms even if it was hidden in the way the story was completed. This deviation indicated the conformity of the narrator and his intention to accept the dominant role of the teacher. The evolution of the story reveals the pedagogic relation and at the same time the negotiation of the shaping of the pupil's consciousness.

\section{References}

Abrahamson, M. (1966). Interpersonal Accommodation. Princeton, New Jersey: Van Nostrand.

Bakhtin, M. (2003). Speech Genres and other Late Essays. In P. Morris (ed.), The Bakhtin Reader (pp. 81-87). London: Arnold.

Bernstein, B. (1990). The structure of pedagogic discourse. London: Routledge. http://dx.doi.org/10.4324/9780203011263 
Bernstein, B. (1996). Pedagogy, Symbolic Control and Identity: Theory, Research, Critique. London: Taylor \& Francis.

Bernstein, B. (2003). Class, Codes and Control. The Structuring of Pedagogic Discourse, 4. London: Routledge.

Bourdieu, P. (1990). The Logic of Practice. Cambridge: Polity Press.

Bruner, J. (1986). Actual minds, possible worlds. Cambridge: Harvard University Press.

Christie, F. (2002). Classroom Discourse Analysis. A Functional Perspective. London: Continuum.

Cooper, B., \& Dunne, M. (2000). Assessing children's mathematical knowledge. Social class, sex and problem solving. Buckingham: Open University Press.

Eggins, S., \& Slade, D. (1997). Analysing Casual Conversation. London: Cassell.

Fairclough, N. (1995). Critical Discourse Analysis: The Critical Study of Language. London: Longman.

Freedman, A., \& Medway, P. (1994). Learning and Teaching genre. Portsmouth, NH: Boynton/Cook.

Gutierrez, K., Baquedano-Lopez, P., \& Tejeda, C. (1999). Rethinking Diversity: Hybridity and Hybrid Language Practices in the Third Space. Mind, Culture and Activity, 6(4), 286-303. http://dx.doi.org/10.1080/10749039909524733

Halliday, M. A. K. (1978). Language as Social Semiotic: The Social Interpretation of Language and Meaning. London: Arnold.

Halliday, M. A. K. (1994). An Introduction to Functional Grammar. London: Arnold.

Hewitt, J. (2007). Self and Society. A Symbolic Interactionist Social Psychology. Boston: Pearson Education, Inc.

Lyle, S. (2002). Talking to Learn: The Voice of Children, Aged 9-11, Engaged in Role-Play. Language and Education, 16, 303-317. http://dx.doi.org/10.1080/09500780208666833

Macken-Horarik, M. (2002). "Something to shoot for": A Systemic Functional Approach to teaching Genre in Secondary School Science. In A. Johns (ed.), Genre in the Classroom: Multiple Perspectives (pp. 17-42). N. J. \& London: Lawrence Erlbaum Associates.

Martin, J., \& Rose, D. (2007). Working with Discourse. Meaning Beyond the Clause. London: Continuum.

Martin, J. (1984). Language, register and genre. In F. Christie (ed) Children Writing: Reader (pp. 21-30). Deakin University Press: Geelong.

Martin. J., \& Rothery, J. (1986). Writing Project Report No 4. Linguistics Department, University of Sidney.

Ochs, E., \& Taylor, C. (1992). Family narrative as political activity. Discourse and Society, 3(3), 301-340. http://dx.doi.org/10.1177/0957926592003003003

Ochs, E. (1997). Narrative. In T. van Dijk (ed), Discourse as Structure and Process (pp.185-207). London: Sage.

Papadopoulou, M., \& Poimenidou, M. (2008). The Contribution of Play in the Emergence of Hybrid Genres in Kindergarten. Special Issue of the Odense Working Papers in Language and Communication, edited by Nina Norgaard, online Journal, 621-633.

Plum, G. A. (1988). Types of spoken narrative. Paper presented at the LERN conference: Working with Genre. University of Technology, Sydney.

Scheibe, K. (1995). Self Studies. The psychology of self and identity. Westport: Praeger Publishers.

Swales, J. (1990). Genre analysis: English in academic and research settings. Cambridge: Cambridge University Press.

Taylor, C. (1995). "You think it was a fight? Co-constructing meaning, face, and family in everyday narrative activity", Research on Language and Social Interaction, 28(3), 283-317. http://dx.doi.org/10.1207/s15327973rlsi2803_6

van Dijk, T. A. (2008). Critical Discourse Analysis. In D. Schiffrin, D. Tannen \& H. Hamilton (eds) The Handbook of Discourse Analysis. Oxford: Blackwell Publishing. 